Published every April, August and December

JURNAL RISET AKUNTANSI \& KEUANGAN

ISSN:2541-061X (Online). ISSN:2338-1507(Print). http://ejournal.upi.edu/index.php/JRAK

\title{
Analisis Determinan Good Government Governance Serta Implikasinya Pada Kualitas LAKIP
}

\author{
Lalu Danny Segara
}

Fakultas Ekonomi dan Bisnis, Universitas Mataram, Mataram, Indonesia

\begin{abstract}
This study aimed to analyze the influence of morality, reliability, and commitment to the GGG and the implications on the quality LAKIP. The low performance of the apparatus in the delivery of LAKIP an inconsistency GGG that impact on the quality LAKIP. The population is involved in reporting apparatus LAKIP in thirteen units of the Ministry of Religious work throughout Central Lombok district. The sample is determined by purposive sampling method amounted to 50 respondents. analysis using SMART Partial Least Square (PLS) Version 2.0. Findings show GGG influenced by morality and reliability, but is not influenced by the commitment apparatus. Other findings indicate GGG has implications for the quality LAKIP. Implications of the study is useful as consideration of the leadership ranks of the Ministry of Religious Affairs, in optimizing GGG.
\end{abstract}

Keywords: apparatus; commitment; good goverment governance; morality.

Abstrak. Penelitian ini bertujuan menganalisis pengaruh moralitas, kehandalan, dan komitmen terhadap GGG dan implikasinya pada kualitas LAKIP. Rendahnya kinerja aparatur dalam penyampaian LAKIP merupakan inkonsistensi GGG yang berdampak pada kualitas LAKIP. Populasi merupakan aparatur yang terlibat dalam pelaporan LAKIP di tiga belas satuan kerja Kementerian Agama se-kabupaten Lombok Tengah. Sampel ditentukan dengan metode purposive sampling berjumlah 50 responden. Analisis menggunakan SMART Partial Least Square (PLS) Versi 2.0. Temuan menunjukkan GGG dipengaruhi oleh moralitas dan kehandalan, tetapi tidak dipengaruhi oleh komitmen aparaturnya. temuan lain mengindikasikan GGG memiliki implikasi terhadap kualitas LAKIP. Implikasi penelitian berguna sebagai pertimbangan jajaran pimpinan Kementerian Agama, dalam mengoptimalkan GGG.

Kata Kunci: aparatur; good goverment governance; komitmen; moralitas

Corresponding author. Email: laludanny@gmail.com

How to cite this article. Segara, L. D. (2017). Analisis Determinan Good Government Governance Serta Implikasinya Pada Kualitas LAKIP. Jurnal Riset Akuntansi Dan Keuangan Program Studi Akuntansi Fakultas Pendidikan Ekonomi Dan Bisnis Universitas Pendidikan Indonesia, 5(1), 1261-1276. https://doi.org/10.17509/jrak.v5i1.6730

History of article. Received: February 2017, Revision: March 2017, Published: April 2017

Online ISSN: 2541-061X. Print ISSN: 2338-1507. DOI :10.17509/jrak.v5i1.6730

Copyright@2017. Published by Jurnal Riset Akuntansi dan Keuangan. Program Studi Akuntansi. FPEB. UPI 


\section{PENDAHULUAN}

\begin{abstract}
Perubahan dan perbaikan kualitas kinerja pemerintah diperlukan untuk mengembalikan dan memulihkan kepercayaan masyarakat. Untuk menjawab perubahan dan perbaikan pengelolaan dan pelaksanaan tugas pemerintahan yang lebih baik Pemerintah diwajibkan untuk menerapkan Good governance pada pemerintahannya. Good governance pada lingkungan pemerintahan sering dikenal dengan istilah Good Government Governance (GGG).
\end{abstract} (Yasminingrum, 2013) menyatakan bahwa Perwujudan good governance membutuhkan dimensi kapasitas yang selama ini cenderung diabaikan dan hanya mendapat perhatian minor adalah moral,. Pengembangan aparatur pemerintah harus dimulai dari jenjang pimpinan yang mampu membangun pentingnya moral.

Penyelenggaraan Pemerintahan secara baik (good-governance) dan bersih (cleangovernment) tentunya berimplikasi terhadap kompetensi aparatur yang dimensinya mencakup pengetahuan, keterampilan dan sikap yang memerlukan unsur-unsur mendasar antara lain adalah unsur Kehandalan dari pelaku dan penyelenggara pemerintahan. Terabaikannya unsur Kehandalan dalam menjalankan tugas dan fungsi organisasi pemerintahan akan berdampak kepada menurunnya kualitas penyelenggaraan pemerintahan. (Mulyati, 2012) mengatakan bahwa Birokrasi pemerintah harus dijalankan dengan semangat profesionalitas yang tinggi yaitu oleh orang-orang yang memiliki kehandalan dalam pengetahuan (Knowledge), ketrampilan (skill) dan serta sikap (attitude) yang tinggi.

Sumber daya manusia adalah aset organisasi yang harus dijaga dan dipelihara agar aparatur yang berkualitas tetap berada di organisasi, untuk mewujudkan hal tersebut aparatur harus memiliki komitmen. (Hutapea \& Widyaningsih, 2017) Mengatakan Salah Satu upaya pemerintah menghadapi berbagai tuntutan publik adalah dengan menjalankan visi dan misi pemerintahannya serta berkomitmen yang tinggi guna untuk mewujudkan cita-cita dan tujuan bangsa bernegara, sebagaimana yang diamanatkan dalam pembukaan Undang-Undang Dasar 1945.

Aparatur yang berkomitmen dan berkualitas biasanya selalu dapat diandalkan dan akan mencurahkan kemampuannya secara maksimal. Edy Topo Ashari (2010) menyatakan bahwa hanya pegawai negeri yang berkualitas tinggi dan memiliki komitmen profesional yang dapat mengembangkan berbagai upaya serta kebijakan untuk menumbuhkan kemandirian masyarakat, dan karenanya memperoleh respek yang tinggi dari masyarakat.

(Pratolo, 2011) mengatakan bahwa Dalam penerapannya $G G G$ dikenal dengan adanya lima prinsip utama, menyebutkan lima prinsip utama dari $G G G$, yaitu transparansi, akuntabilitas, tanggung jawab, independensi, dan keadilan. Sebagai bentuk penerapan prinsip Akuntabilitas dan transparansi tersebut Pemerintah melalui ("Peraturan Menteri PAN-RB No 29 Tahun 2010," n.d.) menyatakan bahwa pencapaian tujuan dan sasaran strategi dilaksanakan melalui penyusunan (Laporan Akuntabilitas Kinerja Pemerintah) LAKIP. LAKIP akan menggambarkan pencapaian rencana strategik, rencana kinerja, penetapan kinerja, dan pengukuran kinerja berperan sebagai alat kendali penilaian kualitas serta alat pendorong terwujudnya $G G G$.

LAKIP yang disampaikan sesuai dengan ketentuannya menjadi indikasi adanya penerapan prinsip-prinsip $G G G$. Maka upaya dalam internal Kementerian Agama khususnya untuk bisa menyusun dan menyampaikan LAKIP sesuai dengan ketentuan merupakan bentuk nyata dan upaya mencapai $G G G$. Namun hal tersebut masih belum berjalan optimal. Fakta yang terjadi menunjukkan penyusunan dan penyampaian LAKIP masih dihadapkan pada berbagai persoalan. Dari hasil Evaluasi yang dilaksanakan oleh Sekretariat Jenderal Kementerian Agama Republik Indonesia, 
menyebutkan bahwa terdapat kendala dalam penyusunan dan pelaporan capaian kinerja.

Mengacu pada surat edaran tersebut, Kanwil Kemenag Provinsi NTB termasuk salah satu Satker yang belum menyusun dan menyampaikan LAKIP. Belum terpenuhinya penyusunan dan penyampaian LAKIP yang akurat yang dimutahirkan secara berkala pada Kanwil Kementerian Agama Provinsi NTB dipengaruhi oleh penyampaian LAKIP seluruh Kantor Kementerian Agama yang berada pada kabupaten/kota di wilayah Provinsi NTB. Data pada Kanwil Kementerian Agama Provinsi NTB (2016), ditemukan bahwa Kantor Kementerian Agama Kabupaten Lombok Tengah merupakan satker koordinator yang memiliki capaian Ketepatan waktu penyampaian LAKIP dengan trend prosentase penurunan yang cukup drastis dari tahun 2012 sampai dengan tahun 2015, dari 61,54 persen pada Tahun 2012 turun menjadi 7,69 persen pada Tahun 2015. Begitu pula pada sisi ketidak tepatan tujuan penyampaian LAKIP mengalami trend peningkatan prosentase, dari 38,46 persen di tahun 2012 menjadi 93,31 persen pada Tahun 2015.

Hal ini merupakan indikasi adanya berbagai permasalahan, dan hambatan serta inkonsistensi dalam implentasi $G G G$. Hambatan dalam implementasi $G G G$ menunjukkan kemungkinan adanya variabel lain yang berpengaruh, yakni Moralitas, Kehandalan dan komitmen Aparatur. Dengan adanya Moralitas, Kehandalan dan Komitmen aparatur yang konsisten diharapkan implementasi $G G G$ dapat berjalan secara optimal. maka hal ini memberikan motivasi serta dorongan kepada peneliti untuk melakukan penelitian lebih lanjut.

\section{KAJIAN LITERATUR}

\section{Agency Theory}

Jensen dan Meckling (1976) dalam (Santoso \& Pambelum, 2008) menyatakan bahwa bahwa hubungan keagenan sebagai sebuah kontrak dimana satu atau lebih (principal) menyewa orang lain (agent) untuk melakukan beberapa jasa untuk kepentingan mereka dengan mendelegasikan beberapa wewenang pembuatan keputusan kepada agen. Demikian halnya menurut (Tisna \& Agustami, 2016) Agency terori atau Teori Agen yaitu Pemilik Perusahaan yang hakikatnya memiliki modal atau memberikan kewenangan kepada seorang manager professional untuk mengelola perusahaanya dengan baik demi mendapatkan keuntungan yang tinggi.

(Santoso \& Pambelum, 2008) mengatakan bahwa hubungan antara masyarakat (prinsipal) dengan pemerintah (agen) merupakan salah satu contoh bentuk dari teori keagenan. Prinsipal memberikan wewenang pengaturan kepada agen, dan memberikan sumber daya kepada agen. Sebagai wujud pertanggung jawaban atas wewenang yang diberikan, agen memberikan laporan pertanggungjawaban kepada prinsipal

\section{Moralitas}

Menurut Kamus Bahasa Indonesia, moral berarti ajaran baik buruk yang diterima umum mengenai perbauatan, sikap, kewajiban, dan sebagainya (Nurdin, 2001). Kata moral selalu mengacu pada baik dan buruknya perbuatan manusia sebagai manusia. Moralitas berfokus pada perilaku manusia yang benar dan salah, sehingga moralitas berhubungan dengan pertanyaan bagaimana seseorang bertindak terhadap orang lain (Al Haryanto, 2001). Dengan kata lain, moralitas adalah tekad untuk mengikuti apa yang ada dalam hati manusia dan disadari sebagai kewajiban mutlak (Aranta, 2013).

\section{Kehandalan}

(Parasuraman, Valarie A, \& Leonard L, 1985) mengatakan bahwa, "Kehandalan adalah kemampuan untuk memberikan pelayanan yang dijanjikan dengan tepat (accurately) dan kemampuan untuk dipercaya (dependably), terutama memberikan jasa secara tepat waktu (ontime), dengan cara yang sama sesuai dengan jadual yang telah dijanjikan dan tanpa melakukan kesalahan setiap kali".

Dalam menjawab tuntutan $G G G$ maka dibutuhkan Aparatur yang unggul selalu mempersiapkan dirinya dengan pengetahuan praktis terbaik, dan selalu menjadi pembelajar 
seumur hidup untuk tujuan meningkatkan kualitas profesionalisme dirinya terhadap tugas dan tanggung jawabnya.

\section{Komitmen}

Menurut Kamus yang ditulis oleh Anshori, komitmen berasal dari kata commit, artinya melakukan, mempercayakan dan menyerahkan. Selanjutnya Robert Stringer dalam (Wirawan, 2008) mengatakan bahwa komitmen merefleksikan perasaan bangga anggota terhadap organisasinya dan derajat keloyalan terhadap pencapaian tujuan organisasi. Pendapat di atas mengemukakan bahwa komitmen itu merupakan suatu sikap yang ditunjukkan seseorang dalam tanggung jawabnya sebagai anggota organisasi.

\section{Good Government Governance}

Pengertian $G G G$ adalah suatu konsep pendekatan yang berorientasi kepada pembangunan sektor publik oleh pemerintah yang baik (Mardiasmo, 2008). Kondisi ini berupaya untuk menciptakan suatu penyelenggaraan pembangunan yang solid dan bertanggung jawab sejalan dengan prinsip demokrasi, efesiensi, pencegahan korupsi, baik secara politik maupun administrasi. $G G G$ sebagai penyelenggaraan pemerintahan negara yang solid dan bertanggung jawab, serta efisiensi dan efektif dengan menjaga kesinergisan interaksi yang konstruktif diantara domain-domain negara, sektor swasta dan masyarakat.

\section{Kualitas Laporan Akuntabilitas Kinerja Instansi Pemerintah (LAKIP)}

LAKIP merupakan dokumen yang berisi gambaran perwujudan AKIP yang disusun dan disampaikan secara sistematik dan melembaga. Setiap instansi pemerintah berkewajiban untuk menyiapkan, menyusun dan menyampaikan laporan kinerja secara tertulis, periodik dan melembaga. Menurut (LAN \& BPKP, 2004) LAKIP yang berkualitas harus memenuhi prinsip-prinsip laporanyang baik yaitu: (a) Relevan; (b) Accuracy/reliability (akurat dan handal); (c) Consistency/comparability (konsisten/dapat diperbandingkan); traceability (verifikasi/ditelusuri);

Timeliness (Tepat Waktu);

Understandability (dapat dimengerti); (g) Prinsip lingkup pertanggungjawaban; (h) Prinsip prioritas; (i) Prinsip manfaat; (j) Mengikuti standar laporan yang ditetapkan sesuai dengan peraturan Perundang-undangan.

\section{Hubungan Moralitas terhadap implementasi $\boldsymbol{G} \boldsymbol{G} \boldsymbol{G}$}

(Amrizal, 2004) mengemukakan bahwa kepedulian positif dari lingkungan kerja sangat diperlukan dalam membangun suatu etika perilaku dan kultur organisasi yang kuat. Rendahnya kepedulian dan rendahnya moral menyuburkan tindakan kecurangan yang pada akirnya dapat merusak bahkan menghancurkan organisasi. (Syukur, 2012) mengemukakan bahwa beberapa permasalahan aparatur birokrasi pemerintah juga dapat diidentifikasi rendahnya standar moral dan perilaku aparat dalam menjalankan fungsi-fungsi pelayanan. $\mathrm{Hal}$ ini sesuai dengan apa yang dikemukakan oleh (Lukow, 2013) yang menyatakan bahwa Good governance yang efektif menuntut adanya "alignement" (koordinasi) yang baik dan integritas, profesional serta etos kerja dan moral yang tinggi.

$\mathrm{H}_{1}$ : Di duga bahwa Moralitas berpengaruh positif terhadap implementasi $G G G$

\section{Hubungan Kehandalan terhadap implementasi $G G G$}

Kehandalan disini lebih ditujukan kepada kemampuan aparatur dalam memberikan pelayanan yang baik, adil, dan inklusif dan tidak hanya sekedar kecocokan keahlian dengan tempat penugasan. (Mulyati, 2012) mengatakan bahwa birokrasi pemerintah harus dijalankan dengan semangat profesionalisme yang tinggi, yaitu oleh orangorang yang memiliki kehandalan dalam pengetahuan (Knowledge), keterampilan (skill), serta sikap (attitude) yang terpuji.

Kemampuan untuk menggunakan konsep dan filosofi matematika secara umum, serta menguasai logika matematika, akan menjadi hal penting untuk kesuksesan dalam 
peningkatan kinerja. (Syukur, 2012) menyatkan bahwa. "Bahwa kunci sukses Good local governance pada akhirnya akan berpulang kepada tingkat kompetensi sumber daya aparatur birokrasi pemerintah daerah itu sendiri. Pemerintah daerah saat sekarang ini harus memiliki cukup sumber daya aparatur yang professional dan handal, yang mampu menghadapi keseluruhan kompleksitas tuntutan dan kebutuhan masyarakat (spirit zaman) sekarang".

Kehandalan pegawai untuk memberikan integritas pribadi dalam meningkatkan tata kelola pemerintahan dengan prinsip-prinsip terbaik, akan menjadikan pegawai sebagai keunggulan sempurna dalam segala hal yang perusahaan lakukan, untuk upaya peningkatan kinerja terbaik.

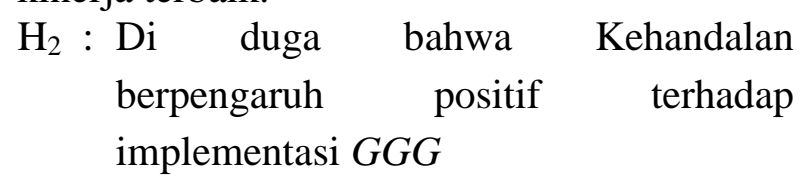

\section{Hubungan Komitmen terhadap implementasi $G G G$}

(Indrajit, 2004) menyatakan bahwa Komitmen atau rasa keterkaitan aparatur pemerintah terhadap instansi tempat mereka bekerja dapat berpengaruh pada terciptanya tata pemerintahan yang baik (good governance) pada instansi tersebut. Hal ini disebabkan pelaksanaan good governance mengandalkan aparatur instansi pemerintah sebagai sumber daya utamanya. Seseorang itu mempunyai komitmen, maka ia akan selalu bekerja dengan penuh semangat dan sungguhsungguh, serta akan berusaha menjalin kerjasama yang lebih baik antar sesama organisasi.

Pada dasarnya komitmen karyawan (individu) akan mendorong terciptanya komitmen organisasi (Prasetyono \& Kompyurini, 2007), (Karadal, Ay, \& Cuhadar, 2008), (J. T. Keban, 2008), juga menyatakan bahwa komitmen organisasi diperlukan untuk peningkatan kinerja organisasi melalui kesadaran individu dalam organisasi akan hak dan kewajibannya tanpa melihat jabatan dan kedudukan. Sehingga tujuan organisasi dapat terlaksana dan tercapai seoptimal mungkin demi keberhasilan organisasi tersebut. (Y. T. Keban, 2004) menyatan bahwa Komitmen para pemimpin atau manajer organisasi publik terhadap pentingnya penilaian suatu kinerja. Bila mereka selalu memberikan komitmen yang tinggi terhadap efektivitas penilaian kinerja, maka para penilai yang ada dibawah otoritasnya akan selalu berusaha melakukakan penilaian secara tepat dan benar

$\mathrm{H}_{3}$ : Di duga bahwa Komitmen berpengaruh positif terhadap $G G G$

\section{Hubungan implementasi $G G G$ terhadap Kualitas LAKIP}

(Pratolo, 2011) menyatakan bahwa $G G G$ mengandung beberapa prinsip didalamnya. Penerapan prinsip-prinsip $G G G$ pada dasarnya merupakan perwujudan keamanan pengelola dalam menjalankan tugas yang diamanatkan kepadanya dan kejujuran dalam pelaporan keuangan Begitu juga menurut (Sari, 2012) mengungkapkan bahwa tata kelola pemerintahan yang baik menghendaki pemerintah dijalankan dengan mengikuti prinsip-prinsip pengelolaan yang baik seperti transparansi, keterbukaan, akuntabilitas, partisipasi, keadilan, dan kemandirian.

(Hardiwinoto, 2005) mengungkapkan bahwa prinsip-prinsip tersebut dapat mencerminkan kinerja pemda untuk suatu periode tertentu. Apabila prinsip itu diterapkan dalam suatu pemerintahan daerah, maka $G G G$ akan tercapai dan kinerja sebuah pemerintah daerah akan menjadi lebih baik. Salah satu komponen vital dalam pencapaian good government governance adalah akuntabilitas publik. United Nation Development Program (UNDP) (LAN \& BPKP, 2004), (Kusmayadi, 2009) menyatakan bahwa akuntabilitas merupakan elemen terpenting dan menjadi prinsip pokok dalam 
rangka terwujudnya tata kelola pemerintah yang baik (good governance).
$\mathrm{H}_{4}$ : Di duga bahwa implementasi $G G G$ berpengaruh positif terhadap Kualitas Laporan Akuntabilitas kinerja.

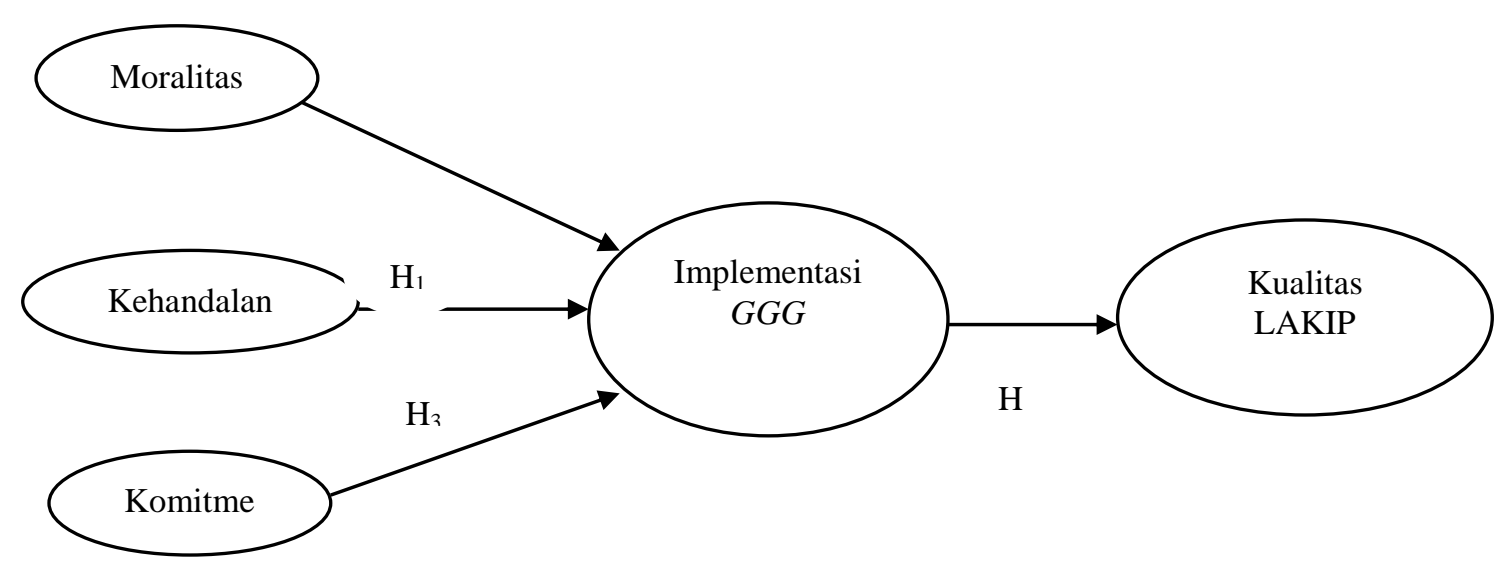

Gambar 1. Kerangka Konsep Penelitian

\section{METODOLOGI PENELITIAN}

\section{Populasi dan Sampel}

Populasi adalah wilayah generalisasi yang terdiri atas obyek/subyek yang mempunyai kualitas dan karakteristik tentang apa yang ditetapkan oleh peneliti untuk dipelajari dan kemudian ditarik kesimpulan (Sugiyono, 2011). Populasi dalam penelitian ini adalah Seluruh Aparatur atau Pejabat yang terlibat dalam penyusunan dan pelaporan LAKIP di tiga belas Satker Kementerian Agama se-Kabupaten Lombok Tengah.

Sampel adalah bagian dari jumlah dan karakteristik yang dimiliki oleh populasi (Sugiyono, 2012). Teknik pengambilan sampel dalam penelitian ini dilakukan dengan metode Purposive sampling yaitu pengambilan sampel berdasarkan suatu pertimbangan/kriteria tertentu sesuai dengan yang dikehendaki peneliti (Sugiyono, 2011). (Sekaran, 2013) juga berpendapat Purposive sampling digunakan karena informasi yang akan diambil berasal dari sumber yang sengaja dipilih berdasarkan kriteria yang telah ditetapkan peneliti.

\section{Jenis dan Sumber Data}

Jenis data dalam penelitian ini yaitu data primer dan sekunder. Data primer diperoleh dari jawaban hasil penyebaran kuesioner kepada pihak-pihak terkait pada penyusunan laporan akuntabilitas kinerja, dalam hal ini Aparatur Sipil Negara pada satuan kerja Kementerian Agama se- Kab Lombok Tengah. Data sekunder dapat berupa hasil dokumentasi, catatan, buku yang berkaitan dengan obyek penelitian, seperti gambaran umum lokasi penelitian maupun data terkait Laporan Akuntabilitas kinerja pada setiap satuan kerja.

\section{Definisi dan Pengukuran Variabel Variabel Endogen}

Variabel yang dipengaruhi oleh variabel lain dalam suatu model penelitian. Variabel Endogen dalam penelitian ini adalah Implementasi $G G G$ dan Kualitas Laporan Akuntabilitas kinerja

\section{Implementasi GGG}

Implementasi $\quad G G G$ merupakan penerapan aspek-aspek fungsional dari pemerintahan yang efektif dan efisien dalam pelaksanaan tugasnya untuk mencapai tujuan 
organisasi. Berdasarkan hal tersebut, dimensi yang digunakan untuk mengukur variabel Implementasi $G G G$ adalah: (a) Dimensi Transparansi. diukur dengan keterbukaan (disclosure), tepat waktu (timely basis), serta benar (accurate); (b) Dimensi Akuntabilitas, diukur dengan pengawasan yang efektif, distribusi dan keseimbangan kekuasaan (distribution and balance of power); (c) Dimensi Pertanggung jawaban, diukur dengan rasa tanggungjawab, mematuhi hukum dan tanggap pada ketentuan peraturan yang berlaku; (d) Dimensi Keadilan, diukur dengan pencegahan dari rekayasa pelaporan dan transaksi-transaksi yang bertentangan dengan peraturan yang berlaku; (e) Dimensi indepedensi, diukur dengan satuan kerja/organisasi dapat memastikan tidak adanya intervensi atau tekanan dari pihak manapun dalam penyusunan laporan akuntabilitas kinerja.

\section{Kualitas LAKIP}

Dalam konteks organisasi pemerintah, akuntabilitas publik merupakan pemberian informasi dan pengungkapan informasi (disclosure) atas aktivitas dan kinerja finansial pemerintah kepada pihak-pihak yang berkepentingan dengan laporan tersebut Pemerintah, baik pusat maupun daerah, harus bisa menjadi subyek pemberi informasi dalam rangka pemenuhan hak-hak publik (Haryanto, Sahmuddin, \& Arifuddin, 2007).

Dimensi yang digunakan untuk variabel Kualitas LAKIP adalah karakteristik kualitatif laporan keuangan sesuai dengan (Peraturan Pemerintah Nomor 71, 2010) yang diukur dengan beberapa indikator, yaitu: (a) Dimensi relevan, diukur dengan melihat manfaat umpan balik, manfaat prediktif, dan lengkap; (b) Dimensi andal, diukur dengan penyajian yang jujur, dan netral; (c) Dimensi tepat waktu, diukur dengan penyajian yang terjadwal, periodik, dan memiliki batas waktu; (d) Dapat diverifikasi, diukur dengan perbandingan dengan periode sebelumnya dan perbandingan dengan satuan kerja lain; (e) Dapat dipahami diukur dengan informasi yang rinci, informasi sesuai kebutuhan dan pemahaman informasi.

\section{Variabel Eksogen,}

Merupakan variabel yang tidak dipengaruhi oleh variabel lainnya dalam model penelitian. Variabel Eksogen dalam penelitian ini adalah Moralitas, Kehandalan, dan Komitmen.

\section{Moralitas}

Moral adalah kualitas dalam perbuatan manusia yang menunjukkan bahwa perbuatan itu benar atau salah, baik atau buruk. Pengukuran moralitas berasal dari model pengukuran moral oleh (Kohlberg, 1969) dalam bentuk instrumen Defining Issues TestTest (DIT) yang dirancang untuk mengukur kapasitas moral kognitif, yaitu tingkat penalaran moral yang mampu dilakukan oleh seorang individu. Moralitas diukur melalui enam butir instrumen yang mengukur setiap tahapan moralitas melalui kasus dilema etika Akutansi. Instrumen ini berbentuk kasus dilema etika akutansi yang dikembangkan lagi dalam penelitian (Dewi, Ayu Ketut Rencana sari, 2014).

\section{Kehandalan}

Menurut (Parasuraman et al., 1985) kehandalan (reliability) adalah kemampuan untuk memberikan pelayanan yang dijanjikan dengan tepat (accurately) dan kemampuan untuk dipercaya (dependably), terutama memberikan jasa secara tepat waktu (ontime), dengan cara yang sama sesuai dengan jadual yang telah dijanjikan dan tanpa melakukan kesalahan setiap kali. Indikator pengukuran dari Kehandalan yaitu : Kecermatan petugas dalam melayani, memiliki standar pelayanan yang jelas, Kemampuan petugas/aparatur dalam menggunakan alat bantu dalam proses pelayanan, dan Keahlian petugas dalam menggunakan alat bantu dalam proses pelayanan.

\section{Komitmen}


Pengertian komitmen karyawant adalah rasa identifikasi, keterlibatan dan loyalitas yang dinyatakan oleh seorang pegawai terhadap organisasinya, Steers dalam (Kuntjoro, 2002). (Wulandari, 2013) menyatakan bahwa komitmen diukur dengan berdasarkan tiga dimensi yaitu: komitmen afektif, komitmen berkelanjutan, dan komitmen normatif. (1) Komitmen afektif, yaitu komitmen yang berkaitan dengan adanya keinginan untuk terikat pada organisasi. Pengukuran Komitmen Afektif menggunakan indikator : (a) kepatuhan, (b) rasa hormat, (c) janji dan sumpah; (2) Komitmen Berkelanjutan, yaitu komitmen yang timbul karena adanya kebutuhan rasional. Pengikuran Komitmen Berkelanjutan, menggunakan indikator : (a) loyalitas, (b) kesetiaan, (c) keterikatan; (3) Komitmen Normatif, yaitu komitmen yang bersumber pada norma yang ada dalam diri individu, yang berisi keyakinan individu akan tanggung jawab terhadap organisasi, dirinya merasa harus bertahan karena alasan loyalitas. Pengukuran Komitmen Normatif, menggunakan dengan indikator : (a) disiplin, (b) tanggung jawab, (c) kerja keras.

\section{Metode Analisis Data}

Tahapan Analisis data yang digunakan dalam penelitian ini dengan menggunakan analisis statistik deskriptif, selanjutnya pengujian validitas dan reliabilitas konstruk melalui evaluasi outer model serta evaluasi inner model dengan menggunakan program Smart PLS versi 2.0. Evaluasi outer model dilakukan untuk menilai validitas dan reliabilitas model. Sedangkan Evaluasi inner model bertujuan untuk memprediksi hubungan antara konstruklaten dengan konstruk lainnya. Uji hipotesis dilakukan dengan melihat Estimate for Path Coefficients, melalui menu bootstrapping pada program Smart PLS.

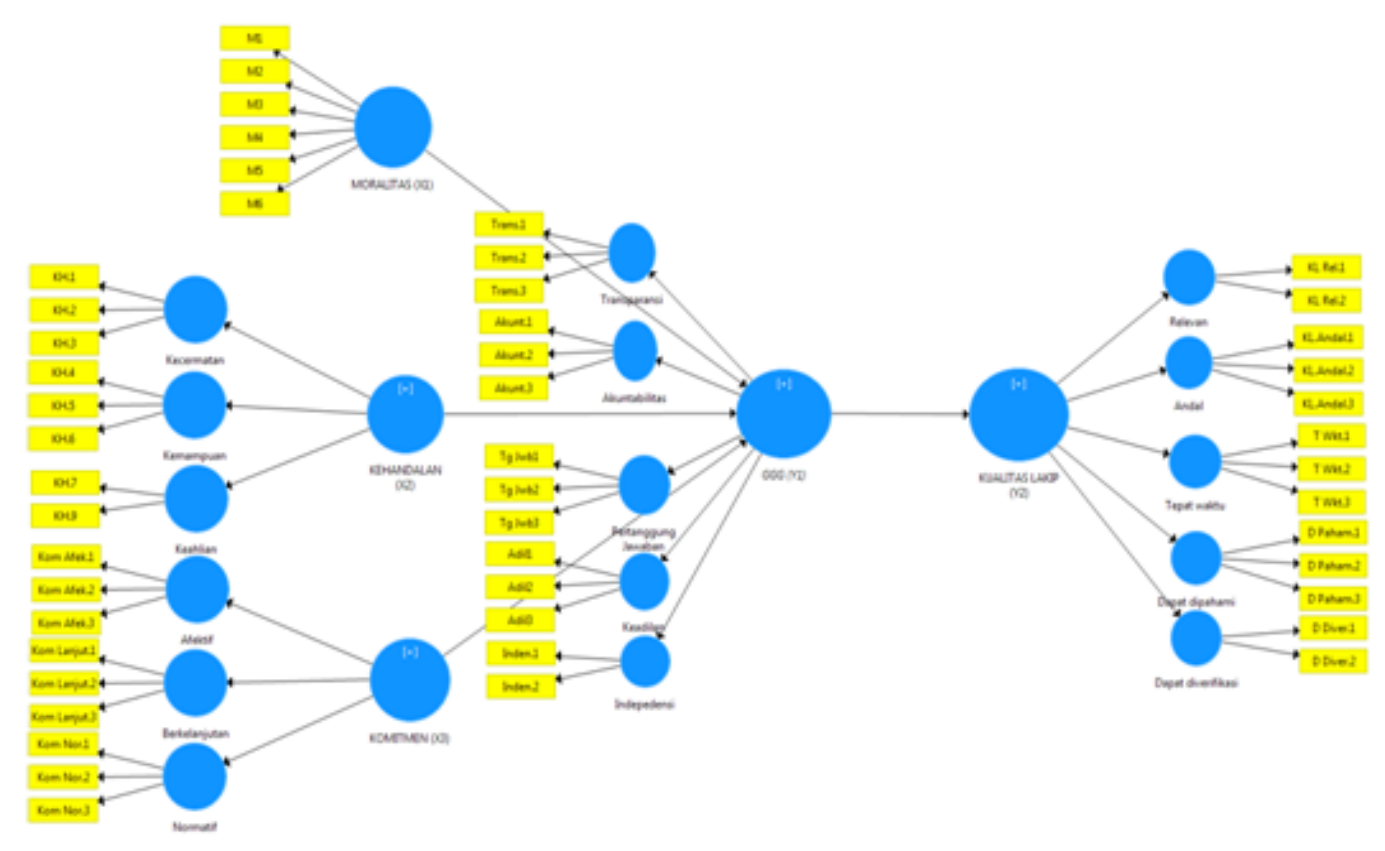

Gambar 2. Model Struktural dan Pangukuran Second Order dengan PLS

HASIL DAN PEMBAHASAN

Analisis Statistik Deskriptif Deskriptif Variabel Moralitas
Hasil pengukuran menunjukkan bahwa dari 50 responden terdapat 14 orang dengan total skor $>17$, sedangkan 36 orang lainnya memperoleh total skor $<17$. Dengan demikian 28 persen responden memiliki level 
moral yang tinggi (level post-conventional) dan 72 persen responden memiliki level moral yang rendah (level pre-conventional).

\section{Deskriptif Variabel Kehandalan}

Secara umum, berdasarkan nilai ratarata tanggapan responden secara keseluruhan, Kehandalan yang dimiliki oleh aparatur dapat dikategorikan baik dengan nilai rata-rata variabel sebesar 160,3. Hal tersebut menunjukkan bahwa SDM yang dimiliki oleh Aparatur memiliki kemampuan, keterampilan dan keahlian dalam memberikan pelayanan publik yang responsif, transparansi, efektivitas dan efesien.

\section{Deskriptif Variabel Komitmen}

Berdasarkan tabel diatas penilaian responden pada dimensi komitmen afektif (pernyataan 28 - 30) bernilai 170,7. Maka, berdasarkan kategori nilai rata-rata yang berarti masuk dalam kriteria sangat baik. hal ini menunjukkan bahwa responden mempunyai kepatuhan dan rasa hormat yang sangat tinggi terhadap organisasinya. Pada dimensi Komitmen berkelanjutan dengan indikator loyalitas dan kesetiaan (pernyataan 31 - 33) yang benilai sebesar 161,7 berarti termasuk dalam kriteria baik. hal ini menandakan bahwa aparatur mempunyai loyalitas dan kesetian yang baik. Terdapat ikatan secara emosional dan berusaha untuk tetap mengabdi walaupun mendapatkan tawaran pekerjaan di tempat yang lain.

Begitu juga pada dimensi Komitmen normatif (pernyataan 34 - 36) dengan nilai rata-rata 161,3 termasuk dalam kriteria baik. Sehingga dapat dikatakan bahwa responden memiliki disiplin dan tanggung jawab yang baik terhadap organisasinya, masalah perusahaan merupakan masalah karyawan juga, serta selalu berusaha dan berupaya maksimal untuk mencapai tujuan organisasi.

\section{Deskriptif Variabel GGG}

Hasil pengukuran terlihat total skor ratarata untuk variabel implementasi $G G G$ sebesar 172,2 dengan demikian tergolong dalam kriteria sangat baik, artinya secara umum implementasi $G G G$ pada satuan Kerja di lingkungan Kementerian Agama se-Kab Lombok tengah telah berjalan sangat baik, responden sudah melaksanakan prinsipprinsip tata kelola kepemerintahan dengan sangat baik.

\section{Deskriptif Variabel Kualitas LAKIP}

Tanggapan responden terhadap variabel kualitas LAKIP memiliki nilai rata-rata 156 , yang berarti secara umum tergolong pada kriteria baik. Hal ini mengindikasikan bahwa LAKIP sudah memiliki kualitas yang baik, dilihat dari sisi relevansi, keandalan, ketepatan waktu, dapat dipahami dan dapat diverifikasi.

\section{Uji Validitas dan Reabilitas Evaluasi Outer Model}

Outer model dengan indikator reflektif dievaluasi melalui convergent validity, yang dapat dilihat dari outer loading dari masingmasing indikator variabel. Indikator dikatakan mempunyai reabilitas yang baik, jika nilai outer loading di atas 0.7. (Ghozali, 2014) menyatakan bahwa nilai outer loading masih dapat ditolerir hingga 0.50 dan dibawah dari nilai 0.50 dapat didrop dari analis.

Tabel 1. Evaluasi Outer Model Variabel Moralitas

\begin{tabular}{|c|c|c|c|c|}
\hline \multirow{2}{*}{$\frac{\text { DIMENSI }}{\text { No. Item }}$} & \multirow{2}{*}{ INDIKATOR } & \multicolumn{2}{|c|}{ LOADING FAKTOR } & \multirow[b]{2}{*}{ KETERANGAN } \\
\hline & & NILAI & SYARAT & \\
\hline 1 & M.1 & 0,708 & $>0,6$ & Memenuhi convergent validity \\
\hline 2 & M.3 & 0.850 & $>0,6$ & Memenuhi convergent validity \\
\hline 3 & M.5 & 0.873 & $>0,6$ & Memenuhi convergent validity \\
\hline
\end{tabular}

Sumber : Hasil Pengolahan Data (Running) dengan PLS 2.0

Tabel 2. Evaluasi Outer Model Variabel Kehandalan 


\begin{tabular}{ccccc}
\hline DIMENSI & \multirow{2}{*}{ INDIKATOR } & \multicolumn{2}{c}{ LOADING FAKTOR } & \\
\cline { 3 - 4 } No. Item & & NILAI & SYARAT & KETERANGAN \\
\cline { 1 - 1 } Kecermatan & & 0,904 & $>0,6$ & Memenuhi convergent validity \\
37 & KH.1 & 0,940 & $>0,6$ & Memenuhi convergent validity \\
38 & KH.2 & 0.802 & $>0,6$ & Memenuhi convergent validity \\
39 & KH.3 & 0,903 & $>0,6$ & Memenuhi convergent validity \\
Kemampuan & & 0,856 & $>0,6$ & Memenuhi convergent validity \\
40 & KH.4 & 0,860 & $>0,6$ & Memenuhi convergent validity \\
41 & KH.5 & 0,918 & $>0,6$ & Memenuhi convergent validity \\
42 & KH.6 & 0,738 & $>0,6$ & Memenuhi convergent validity \\
\hline
\end{tabular}

Sumber : Hasil Pengolahan Data (Running) dengan PLS 2

Tabel 3. Evaluasi Outer Model Variabel Komitmen

\begin{tabular}{|c|c|c|c|c|}
\hline \multirow{2}{*}{$\begin{array}{c}\text { DIMENSI } \\
\text { No. Item }\end{array}$} & \multirow{2}{*}{ INDIKATOR } & \multicolumn{2}{|c|}{ LOADING FAKTOR } & \multirow[b]{2}{*}{ KETERANGAN } \\
\hline & & NILAI & SYARAT & \\
\hline Afektif & & 0,789 & $>0,6$ & Memenuhi convergent validity \\
\hline 37 & Kom Afek.1 & 0.851 & $>0,6$ & Memenuhi convergent validity \\
\hline 38 & Kom Afek.2 & 0,845 & $>0,6$ & Memenuhi convergent validity \\
\hline 39 & Kom Afek.3 & 0,878 & $>0,6$ & Memenuhi convergent validity \\
\hline Berkelanjutan & & 0,694 & $>0,6$ & Memenuhi convergent validity \\
\hline 41 & Kom Lanjut.2 & 0,927 & $>0,6$ & Memenuhi convergent validity \\
\hline 42 & Kom Lanjut.3 & 0,927 & $>0,6$ & Memenuhi convergent validity \\
\hline Normatif & & 0,807 & $>0,6$ & Memenuhi convergent validity \\
\hline 43 & Kom Nor.1 & 0,936 & $>0,6$ & Memenuhi convergent validity \\
\hline 44 & Kom Nor.2 & 0,731 & $>0,6$ & Memenuhi convergent validity \\
\hline 44 & Kom Nor.3 & 0,838 & $>0,6$ & Memenuhi convergent validity \\
\hline
\end{tabular}

Sumber : Hasil Pengolahan Data (Running) dengan PLS 2.0

Tabel 4. Evaluasi Outer Model Variabel GGG

\begin{tabular}{|c|c|c|c|c|}
\hline \multirow{2}{*}{$\begin{array}{c}\text { DIMENSI } \\
\text { No. Item }\end{array}$} & \multirow{2}{*}{ INDIKATOR } & \multicolumn{2}{|c|}{$\begin{array}{l}\text { LOADING } \\
\text { FAKTOR }\end{array}$} & \multirow{2}{*}{ KETERANGAN } \\
\hline & & NILAI & SYARAT & \\
\hline Transparansi & & 0,845 & $>0,6$ & Memenuhi convergent validity \\
\hline 37 & Trans.1 & 0,842 & $>0,6$ & Memenuhi convergent validity \\
\hline 38 & Trans. 2 & 0,804 & $>0,6$ & Memenuhi convergent validity \\
\hline 39 & Trans.3 & 0,905 & $>0,6$ & Memenuhi convergent validity \\
\hline Akuntabilitas & & 0,810 & $>0,6$ & Memenuhi convergent validity \\
\hline 40 & Akunt.1 & 0,891 & $>0,6$ & Memenuhi convergent validity \\
\hline 41 & Akunt.2 & 0,922 & $>0,6$ & Memenuhi convergent validity \\
\hline $\begin{array}{c}\text { Pertanggung } \\
\text { Jawaban }\end{array}$ & & 0,792 & $>0,6$ & Memenuhi convergent validity \\
\hline 40 & TgJwb.2 & 8,22 & $>0,6$ & Memenuhi convergent validity \\
\hline 41 & Tg.Jwb.3 & 0,931 & $>0,6$ & Memenuhi convergent validity \\
\hline Keadilan & & 0,811 & $>0,6$ & Memenuhi convergent validity \\
\hline 37 & Adil.1 & 0,795 & $>0,6$ & Memenuhi convergent validity \\
\hline 38 & Adil.3 & 0,916 & $>0,6$ & Memenuhi convergent validity \\
\hline
\end{tabular}




\begin{tabular}{ccccl}
\hline Independensi & & 0,873 & $>0,6$ & Memenuhi convergent validity \\
40 & Inden.1 & 0,963 & $>0,6$ & Memenuhi convergent validity \\
41 & Inden.2 & 0,953 & $>0,6$ & Memenuhi convergent validity \\
\hline
\end{tabular}

Sumber : Hasil Pengolahan Data (Running) dengan PLS 2.0

Tabel 5: Evaluasi Outer Model Variabel Kualitas LAKIP

\begin{tabular}{ccccc}
\hline DIMENSI & \multirow{2}{*}{ INDIKATOR } & \multicolumn{2}{c}{ LOADING FAKTOR } & \\
\cline { 3 - 4 } No. Item & & NILAI & SYARAT & KETERANGAN \\
\cline { 1 - 3 } 37 & & 0,712 & $>0,6$ & Memenuhi convergent validity \\
38 & KL Rel.1 & 0,703 & $>0,6$ & Memenuhi convergent validity \\
& KL Rel.2 & 0,916 & $>0,6$ & Memenuhi convergent validity \\
Andal & & & & \\
40 & KLAndal.1 & 0,942 & $>0,6$ & Memenuhi convergent validity \\
41 & KLAndal.2 & 0,967 & $>0,6$ & Memenuhi convergent validity \\
42 & KLAndal.3 & 0,913 & $>0,6$ & Memenuhi convergent validity \\
Tepat Waktu & & 0,911 & $>0,6$ & Memenuhi convergent validity \\
41 & TWkt.2 & 0,880 & $>0,6$ & Memenuhi convergent validity \\
42 & TWkt.3 & 0,825 & $>0,6$ & Memenuhi convergent validity \\
Dapat & & $0,9400,811$ & $>0,6$ & Memenuhi convergent validity \\
Dipahami & & 0,834 & $>0,6$ & Memenuhi convergent validity \\
37 & D Paham.1 & 0,714 & $>0,6$ & Memenuhi convergent validity \\
38 & D Paham.2 & 0,834 & & \\
39 & D Paham.3 & 0,6 & \\
Dapat & & 0,871 & $>0,6$ & Memenuhi convergent validity \\
Diverifikasi & & 0,982 & $>0,6$ & Memenuhi convergent validity \\
40 & D Diver.1 & 0,982 & $>0,6$ & Memenuhi convergent validity \\
41 & D Diver.2 & & & \\
\hline & & &
\end{tabular}

Sumber : Hasil Pengolahan Data (Running) dengan PLS 2.0

(Ghozali \& Latan, 2012) mengatakan bahwa uji reliabilitas untuk membuktikan akurasi, konsistensi, dan ketepatan instrumen dalam mengukur konstruk. Untuk menilai reabilitas konstruk dengan melihat nilai composite reliability. Menurut (Hair, Jr, Black, W.C,
Babin, B.J, Anderson, 2010), rule of thumb yang biasa digunakan untuk menilai reliabilitas konstruk yaitu nilai composite reliability harus lebih besar dari 0,7 meskipun nilai 0,6 dapat diterima (Abdillah \& HM, 2015).

Tabel 6. Composite Reliability

\begin{tabular}{lc}
\hline Variabel dan Dimensi & Composite Reanility \\
\hline Variabel Moralitas & 0,854 \\
Variabel Kehandalan & 0,860 \\
- Kecermatan & 0,914 \\
- Kemampuan & 0,879 \\
Variabel Komitmen & 0,859 \\
- Afektif & 0,894 \\
\hline
\end{tabular}




\begin{tabular}{cc}
\hline - Berkelanjutan & 0,924 \\
- Normatif & 0,876 \\
Variabel GGG & 0,914 \\
- Transparansi & 0,888 \\
- Akuntabilitas & 0,902 \\
- Pertanggung Jawaban & 0,970 \\
- Keadilan & 0,847 \\
- Independensi & 0,957 \\
Variabel Kualitas LAKIP & 0,930 \\
- Relevan & 0,798 \\
- Andal & 0,958 \\
- Tepat Waktu & 0,842 \\
- Dapat Dipahami & 0,838 \\
- Dapat Diversifikasi & 0,982 \\
\hline
\end{tabular}

Sumber : Hasil Pengolahan Data (Running) dengan PLS 2.0

\section{Evaluasi Inner Model}

(Ghozali, 2014) menyatakan bahwa $R$ square digunakan untuk menilai pengaruh konstruk laten independen tertentu terhadap konstruk laten dependen apakah mempunyai pengaruh yang substantive. Semakin tinggi nilai $R$-square berarti semakin baik model prediksi dari model penelitian yang diajukan (Abdillah \& HM, 2015)

Tabel 7. R-Square

\section{Konstruk}

\section{R-Square}

$\begin{array}{cc}G G G & 0.3755 \\ \text { Kualitas LAKIP } & 0.5257\end{array}$

Sumber : Hasil Pengolahan Data (Running) dengan PLS 2.0

Uji hipotesis dilakukan dengan melihat Estimate for Path Coefficients, melalui menu bootstrapping pada PLS. Nilai $T$ statistic yang ditunjukkan pada tabel path coefficient harus lebih besar dari t-tabel (Abdillah \& HM, 2015). Hipotesis diterima, jika nilai $T$-statistics lebih tinggi daripada nilai T-table $(1,96)$ dengan signifikansi level 5 persen (one tailed).

Tabel 8. Path Coefficients (Mean, STDEV, T-Values)

\begin{tabular}{ccclc}
\hline & $\begin{array}{c}\text { Original } \\
\text { Sample (O) }\end{array}$ & $\begin{array}{c}\text { T Statistics } \\
(|\mathbf{O} / \mathbf{S T E R R}|)\end{array}$ & Hipotesis & Keterangan \\
\hline Moralitas -> GGG & 0.446 & 4.070 & $\mathrm{H} 1$ & $\mathrm{H}$ 1 Diterima \\
Kehandalan -> GGG & 0.403 & 2.280 & $\mathrm{H} 2$ & $\mathrm{H} 2$ Diterima \\
Komitmen -> GGG & -0.087 & 0.453 & $\mathrm{H} 3$ & $\mathrm{H} 3$ Ditolak \\
$G G G$-> Kualitas LAKIP & 0.725 & 12.004 & $\mathrm{H} 4$ & $\mathrm{H} 4$ Diterima \\
\hline
\end{tabular}

Sumber : Hasil Pengolahan Data (Running) dengan PLS 2.0 


\section{Pengaruh Moralitas Implementasi $\boldsymbol{G} G \boldsymbol{G}$}

terhadap

Hasil pengujian hipotesis melalui $P L S$ menunjukkan bahwa nilai $T$-statistics $<\mathrm{t}$ tabel, yaitu $4.07<1.96$. Hal ini menunjukkan bahwa Moralitas berpengaruh positif terhadap implementasi $G G G$. Hasil penelitian ini juga membuktikan apa yang ada dalam hirarki tahap perkembangan moral Kohlberg. Semakin tinggi tahapan moralitas individu (tahapan post-konvensional), semakin individu tersebut memperhatikan kepentingan yang lebih luas dan universal dari pada kepentingan organisasinya semata, apalagi kepentingan individunya.

\section{Pengaruh Kehandalan terhadap Implementasi $\boldsymbol{G} \boldsymbol{G} \boldsymbol{G}$}

Hasil pengujian hipotesis menunjukkan bahwa nilai $T$-statistics > t-tabel, yaitu 2.28 $>$ 1.96. Hal ini menunjukkan bahwa, semakin baik dan semakin memadai Kehandalan aparatur, maka akan semakin mendukung dan meningkatkan implementasi $G G G$.

\section{Pengaruh Komitmen terhadap Implementasi $\boldsymbol{G} G \boldsymbol{G}$}

Hasil pengujian hipotesis menunjukkan bahwa nilai $T$-statistics < t-tabel, yaitu 0.45 $<$ 1.96. Hal ini menunjukkan bahwa Komitmen tidak berpengaruh terhadap implementasi GGG. Hal ini disebabkan karena Komitmen pada individu aparatur yang belum maksimal. Komitmen dan kepedulian aparatur terhadap $G G G$ berbedabeda dan pada umumnya masih rendah, serta di pengaruhi kondisi antar daerah di Indonesia yang sangat beragam membuat setiap daerah memilki kompleksitas masalah governance yang berbeda. Kompleksitas dalam implementasi $G G G$ memerlukan upaya yang sistematis untuk mengebangkan program dan kebijakan mengenai struktur dan praktik dalam melaksanakan $G G G$.

\section{Implikasi implementasi $G G G$ terhadap Kualitas LAKIP}

Hasil pengujian hipotesis menunjukkan bahwa nilai $T$-statistics > t-tabel, yaitu 12.00 $>$ 1.96. Hal ini menunjukkan bahwa implementasi $G G G$ mempunyai implikasi terhadap kualitas LAKIP. Semakin baik implementasi $G G G$, maka akan semakin meningkatkan kualitas LAKIP. Bahwa apabila Pemerintahan dalam menjalankan fungsinya dengan menerapkan prinsip-prinsip $G G G$ dengan maksimal, maka akan menyebabkan Akuntabilitas kinerja Pemerintahan tersebut akan berjalan dengan baik termasuk di dalamnya dan kualitas penyusunan dan penyajan informasi kinerja sebagai bentuk pertanggung jawaban pihak pemerintah kepada kepada publik.

\section{SIMPULAN}

Berdasarkan hasil penelitian terhadap pengujian hipotesis yang dilakukan, maka dapat diambil kesimpulan sebagai berikut: Moralitas berpengaruh positif terhadap implementasi $G G G$. Hal ini disebabkan Moral Kepemimpinan adalah baik buruknya tindakan, sikap dan tingkah laku manusia yang menjalankan kepemimpinan. Kepemimpinan yang memiliki moral yang benar-benar mampu mewujudkan $G G G$ agar terwujud Clean Government, yang dapat menggerakkan roda pembangunan yang pada akhirnya tercapai tujuan nasional.

Kehandalan berpengaruh positif terhadap implementasi GGG. Hal ini disebabkan Penyelenggaraan pemerintahan yang baik $(G G G)$ akan terlaksana apabila sumber daya aparatur negaranya bersih, beribawa, profesional dan bertanggung jawab. Karena semakin baik dan memadai kehandalan aparatur, maka akan semakin mendukung dan meningkatkan implementasi $G G G$. Terakhir Komitmen tidak berpengaruh positif terhadap implementasi $G G G$.

Penelitian ini memberi bukti bahwa komitmen memiliki dimensi yang banyak dan area yang sangat luas. Kurangnya komitmen sikap atau mental aparatur terhadap loyalitas, keberpihakan dan keterlibatan dalam organisasi, termasuk kesetiaan pada organisasi. Seorang aparatur tidak semata mendapatkan penghasilan, tetapi banyak lagi aspek lainnya yang dapat dicapai dari pekerjaannya, seperti status sosial, penghargan dan lain-lain. Komitmen sering 
dipahami secara berbeda serta memilki ciri dan indikator yang bervariasi tergantung cara pandang yang dipergunakan. Kondisi seperti inilah yang mengakibatkan komitmen tidak berpengaruh terhadap implementasi $G G G$.

Implementasi $\quad G G G$ mempunyai implikasi terhadap kualitas LAKIP. Hal ini disebabkan dengan implementasi $G G G$, akan menghasilkan suatu informasi yang lebih komprehensif sehingga hal ini akan bedampak pada kualitas LAKIP yang akan terus meningkat. $G G G$ merupakan sistem mengenai bagaimana suatu organisasi dikelola dan dikendalikan. Dengan penerapan $G G G$ akan membuat sebuah instansi akan meningkatkan kualitas pengambilan keputusan. Semakin baik implementasi $G G G$, maka akan semakin meningkatkan kualitas LAKIP.

\section{Implikasi Penelitian}

Implikasi teoritis, temuan penelitian ini memberikan kontribusi terhadap pemahaman Agency theory. LAKIP yang disusun sesuai dengan SAP akan menyajikan informasi yang relevan, andal, tepat waktu, dapat dipahami dan dapat diverifikasi sehingga bermanfaat sebagai dasar pengambilan keputusan.

Implikasi praktis, para pimpinan satuan kerja hendaknya lebih intensif meningkatkan pemeriksaan dan pengawasan LAKIP di tingkat Satuan kerja sehingga LAKIP yang telah disajikan dapat berkualitas. Selain itu Para pimpinan satuan kerja juga perlu, terus menerus melakukan koordinasi, monitoring dan pembinaan yang dilakukan secara berjenjang oleh Kanwil maupun pusat terhadap satuan kerja di bawahnya dalam hal peningkatan kemampuan Sumber Daya Manusia (SDM) satuan kerja dalam penguasaan aplikasi yang terkait pelaporan LAKIP.

Implikasi kebijakan, dapat digunakan Kepala Kantor Kementerian Agama Kab Lombok Tengah, Kepala Kanwil Kemeterian Agama Provinsi Nusa Tenggara Barat, dan para pimpinan di Kantor Pusat Kementerian Agama khususnya di Sekretaris Jendral sebagai salah satu pertimbangan dalam penentuan kebijakan khususnya yang terkait dengan implementasi $G G G$. Hasil penelitian ini juga dapat menjadi masukan bagi Biro Organisasi dan Tata laksana yang mengembangkan aplikasi Sistem Informasi Performance Kementerian Agama (SIPKA) agar lebih bisa digunakan oleh operator secara optimal.

\section{Arah Penelitian Kedepan}

Penelitian ini hanya meneliti tiga variabel yang mempengaruhi implementasi $G G G$, sehingga kurang mengeksplorasi faktor-faktor lainnya yang mungkin berpengaruh. Penelitian selanjutnya dapat mengembangkan variabel penelitian di luar yang digunakan dalam penelitian ini.

Ruang lingkup pada penelitian ini hanya dilakukan satuan kerja dalam wilayah kerja Kemeterian Agama se-Kabupaten Lombok Tengah, sehingga generalisasi hasil temuan dan rekomendasi penelitian ini kurang dapat diberlakukan bagi Kementerian/Lembaga/Dinas/Istansi yang lain. Penelitian selanjutnya diharapkan dapat memperluas obyek penelitian di luar yang digunakan dalam penelitian ini.

Penelitian ini masih memerlukan penelitian lanjutan dan dilaksanakan secara periodik agar data yang didapatkan lebih progresif dan berkesinambungan.

\section{DAFTAR PUSTAKA}

Abdillah, W., \& HM, J. (2015). Partial Least Square, Alternatif Structural Equation Modeling (SEM) dalam Penelitian Bisnis.

Al Haryanto, Y. (2001). Auditing. In Buku 1, BP STIE YKPN, Yogyakarta.

Aranta, P. Z. (2013). Pengaruh Moralitas Aparat Dan Asimetri Informasi Terhadap Kecenderungan Kecurangan Akutansi (Studi Empiris Pemerintah Kota Sawahlunto). Jurnal Akuntansi, 1(1), 160. https://doi.org/10.1017/CBO978110741 5324.004

Dewi, Ayu Ketut Rencana sari, G. (2014). Pengaruh Moralitas Individu Dan Pengendalian Internal PADA Kecurangan Akutansi (Studi Eksperimen pada Pemerintah Daerah 
Provinsi Bali).

Ghozali, I. (2014). Structural Equation Model: Metode Alternatif dengan Partial Least Square (PLS). In Andi.

Ghozali, I., \& Latan, H. (2012). Partial Least Square, Konsep, Teknik dan Aplikasi SMART PLS 2.0 M3 Untuk Penelitian Bisnis.

Hair, Jr, Black, W.C, Babin, B.J, Anderson, R. . (2010). Multivariate Data Analysis. In Upper Saddle River: Pearson Education. (7th ed.).

Hardiwinoto. (2005). Korelasi Timbal Balik Antara Good Goverment Dengan Good Corporate Governance Menuju Pertumbuhan Ekonomi Yang Dinamis. Jurnal Unimus, 2(1), 1-10.

Haryanto, Sahmuddin, \& Arifuddin. (2007). Akutansi Sektor Pubblik (Cetakan Pe).

Semarang: Universitas Diponegoro.

Hutapea, F. L., \& Widyaningsih, A. (2017). The Impact Of Good Government Governance And Size Of The Legislative On Local Goverment Performance (A Study In Provincial Goverment In Indonesia). Jurnal Akutansi Riset. UPI Bandung, 6(1), 167-180.

Indrajit, R. E. (2004). E-Government Strategi Pembangunan Dan Pengembangan Sistem Pelayanan Publik Berbasis Teknologi Digital. Yogyakarta: Andi Offset.

Karadal, H., Ay, U., \& Cuhadar, M. T. (2008). The Effect of Role Conflict and Role Ambiguity on Job Satisfaction and Organizational Commitment: A Study in the Public and Private Sectors. The Journal of American Academy of Business, Cambridge, 13 (2), 176-181.

Keban, J. T. (2008). Enam Dimensi Strategis Administrasi Publik: Konsep, Teori dan Isu.

Keban, Y. T. (2004). Enam Dimensi Strategis Admistrasi Publik, Konep, Teori, dan Isu.

Kohlberg, L. (1969). Stage and Sequence: The Cognitive-Development Approach Moral Action to Socialization. In Handbook of socialization theory and research (pp. 347-480).

Kuntjoro. (2002). Employee Training and Development. In International Edition, McGraw - Hill, Inc.

Kusmayadi, D. (2009). Pengaruh Pengawasan Intern dan Penatausahaan keuangan Daerah terhadap Good Government , Suervei Pada Pemerintahan Kota Tasikmalaya. Junal Ichsan Gorontalo, 4.

LAN, \& BPKP. (2004). Akuntabilitas Keuangan dan Good Governance. LAN.Jakarta.

Lukow, S. (2013). Eksistensi Good Governance Dalam Sistem Pemerintahan Daerah di Kota Manado. Jurnal Hukum Universitas Sam Ratulangi, 1(5), 130-142. Retrieved from

http://repo.unsrat.ac.id/358/1/EKSISTE

NSI_GOOD_GOVERNANCE_DALA M_SISTEM_PEMERINTAHAN_DAE RAH_DI_KOTA_MANADO.pdf

Mardiasmo. (2008). Akuntansi Sektor Publik.

Mulyati, D. (2012). Manajemen

Pengembangan Sumber Daya Aparatur Eselon III Dalam Rangka Peningkatan Kinerja Individu. Bandung.

Nurdin, M. (2001). Moral dan Kognisi Islam. Bandung: CV Alfabeta.

Parasuraman, A., Valarie A, Z., \& Leonard L, B. (1985). A Conceptual Model of Service Quality and its Implication for future Research. Journal of Marketing, 49, N, 41-50.

Peraturan Menteri PAN-RB No 29 Tahun 2010. (n.d.). Indonesia.

Peraturan Pemerintah Nomor 71. (2010). Standar Akuntasi Pemerintah.

Prasetyono, \& Kompyurini, N. (2007). Analisis Kinerja Rumah Sakit Daerah Dengan Pendekatan Balance Scorecard Berdasarkan Komitmen Organisasi, Pengadilan Intern dan Penerapan PrinsipPrinsip Good Corporate Governance (GCG) (Survey Pada Rumah Sakit Daerah di Jawa Timur). Unhas Makasar: Simposium Nasional Akuntansi X.

Pratolo, S. (2011). Peran Good Goverment Governance Untuk Mewujudkan 
Kinerja Pemerintahan Daerah Dan Kepuasan Masyarakat Di Era Otonomi Daerah Dalam Menghadapi Tantangan Global (Studi pada pemerintah kabupaten dan kota di Daerah Istimewa Yogyakarta) Suryo, (2002), 1-10.

Santoso, U., \& Pambelum, Y. (2008). Pengaruh Penerapan Akuntansi Sektor Publik Terhadap Akuntabilitas Kinerja Instansi Pemerintah Dalam Mencegah Fraud. Administrasi Bisnis, 4(1), 14-33 (ISSN : 0216-1249).

Sari, D. (2012). Pengaruh Sistem Pengendalian Intern Pemerintah, Implementasi Standar Akutansi Sekaran, U. (2013). Research Methods for Business. In United Kingdom: Jhon Wiley \& Sons Ltd.

Sugiyono. (2011). Metode Penelitian Kualitatif Kuantitatif dan R\&D. In Alfabeta Bandung.

Sugiyono. (2012). Metode Penelitian Bisnis. In Alfabeta. Bandung.

Syukur, A. T. (2012). Peningkatan Kompetensi Sumbe Daya Aparatur Birokrasi : Kunci Sukses Good Lokal Governance (Suatu Refleksi Atas Fungsi dan Peran STIA-LAN Makasar

Sebagai Pendidikan Tinggi Kedinasan.

Tisna, G. A., \& Agustami, S. (2016). Pengaruh Good Corporate Governance dan Ukuran Perusahaan Terhadap Kinerja Keuangan Perusahaan (Pada Perusahaan Perbankan Yang Terdaftar Di Bursa Efek Indonesia (BEI) Tahun 2010-2014. Jurnal Riset Akutansi Dan Keuangan. UPI Bandung, 4(2), 94-107.

Wirawan. (2008). Budaya dan iklim organisasi.

Wulandari, N. (2013). Pengaruh partisipasi anggaran dan komitmen organisasi terhadap kinerja aparat pemerintah daerah (Studi empiris pada satuan kerja perangkat daerah Kota Padang), 1-24.

Yasminingrum. (2013). Upaya Pengembangan Moral Aparatur Pemerintah Dalam Mewujudkan Good Governance, 10(854), 177-187.
Pemerintah, Penyelesaian Temuan Audit Terhadap Kualitas Laporan Keuangan Pemerintah Daerah Dan Implikasinya Terhadap Penerapan Prinsip-Prinsip Tata Kelola Pemerintah, 